\title{
University Social Responsibility and Sustainable Development Awareness: The Mediating Effect of Corporate Social Responsibility
} Case of Qassim University

\author{
RAGMOUN Wided \\ Dept. of Business Administration, College of Business and Economics, \\ Qassim University, Burayda, Saudi Arabia
}

Received: July 8, 2019 Accepted: November 3, 2019 Published: November 5, 2019 doi: 10.5296/jsss.v7i1.15760 URL: https://doi.org/10.5296/jsss.v7i1.15760

\begin{abstract}
The aim of this research is to identify the components and practices of university social responsibility (USR) - a concept based on corporate social responsibility - and its impact on development and sustainability. Here, it is necessary to develop a new perception of universities, in which we learn, develop and act. This work results from an exploratory approach based on a literature review and observations at Qassim University. The first stage of this research will adopt a qualitative approach, to identify and understand how USR is defined by the university community. The main goal of this stage is the development of items which will be used to measure USR at Qassim University. The second stage is a quantitative approach applied through administration of a questionnaire. A hypothesis test is elaborated by LISREL 8.52 according to a structural equation model (SEM) in which corporate social responsibility is considered a mediating variable between development and sustainability. From this research, a critical path for USR can be defined based on practices. We will also be able to recommend a pathway for sustainable development based on USR.
\end{abstract}

Keywords: Corporate social responsibility, University social responsibility, Sustainable development, Structural equation model, Mediating effect

\section{Introduction}

Social responsibility (SR) seems to be important for organizations nowadays. In fact, organizations must become more active and contribute to the development of society by developing solutions for a better social environment. Our literature review in this field of research shows that this concept is not sufficient, being difficult to define and apply, and this will be elucidated further in this article. However, in its current state, SR as mentioned by many 
researchers is a static dimension and, for the specific needs of this research, we must admit a dynamic view of this, which can be represented by another concept, termed Corporate Social Responsibility (CSR). The notion of the corporation regains importance because it joins two parts, and supposes interaction and collaboration for the same target.

Baumgartner and Ebner (2006) define CSR as 'an obligation to pursue policies to make decisions and to follow lines of action which are compatible with the objectives and value of society'. University, as a special form of organization, must contribute to generating a CSR: especially if we admit that it constitutes the most important generator of knowledge and awareness. Our principal question here regards how corporate social responsibility can mediate the relation between university social responsibility and development in order to stimulate sustainable development. To attend to this objective, we will suppose that the university, as a traditional approach, must be revisited in order to generate actions for social responsibility. Then, these actions can stimulate sustainable development.

This is particularly important in Saudi Arabia due to Vision 2030, in which sustainable development is one of the main objectives.

As a member of the academic community, we can consider that the university can enhance sustainable development in different ways because it is a generator of knowledge. The question that remains is what kind of knowledge and for which objective. In the traditional view, the academic process is based only on learning and research, and now this traditional way of thinking must be revisited, as it has become more important to adapt the knowledge process to the needs of society for additional benefit.

The general idea was to integrate these concepts: university and social responsibility; as a new approach named university social responsibility, and then to create an operational scale of university social responsibility in terms of practices which stimulate development and sustainability through the emergence of corporate social responsibility.

In the second section, we will try to define concepts of USR in order to determine its practices and tools, then consider corporate social responsibility and finally, sustainable development. The third part of the article will be dedicated to the conceptual framework and hypothesis, while the methodology used will be presented in the fourth section. The fifth part of this article will be devoted to the results and discussion, in order to formulate some recommendations which will be provided in the conclusion.

\section{Literature Review}

\subsection{Corporate Social Responsibility}

To correctly define corporate social responsibility (CSR), we have to firstly define, in the first time, social responsibility in order to understand the origin of this concept.

Chen (2015) argue that 'social responsibility should be embedded into the core value and functions of universities' practices at every level'. In fact, this new orientation is supported and discussed by many researchers, but the questions of how and why are still difficult to understand and to operate.

This is why the concept of CSR has been developed, which seems to be easier to appreciate. In general, this concept for the organization means the necessity to integrate social and environmental concerns with operations and organizational strategy, according to Ruxandra et 
al. (2010), who define a 'win-win situation' between society and the organization if CSR is ensured: the organizations win on reputation and performance, with a social benefit for all partnerships, internal and external.

Baumgartner and Ebner (2006) consider that CSR is 'an obligation to pursue policies to make decisions and to follow lines of action which are compatible with the objectives and value of society'. Kumar and Roy (2015) insist on 'the importance of the impact on society' and actions to undertake to meet this responsibility.

There is a large volume of published studies describing CSR, but we can conclude that the main idea attached to this concept is social well-being, and that there is a consensus according to which CSR is represented as a pyramid of responsibilities; economic, ethical, legal and discretionary (Lo et al., 2017). Economic responsibilities seem to be related to goods and services, while legal factors relate to law and rules to ensure respect for social contracts, ethical responsibility represents social norms which must be adopted in the social context, and on the top of the pyramid is discretionary responsibility, which depends on the firm in terms of voluntary judgement and commitment towards society. Caroll (1979) argues that these dimensions of CSR are interdependent and can coexist.

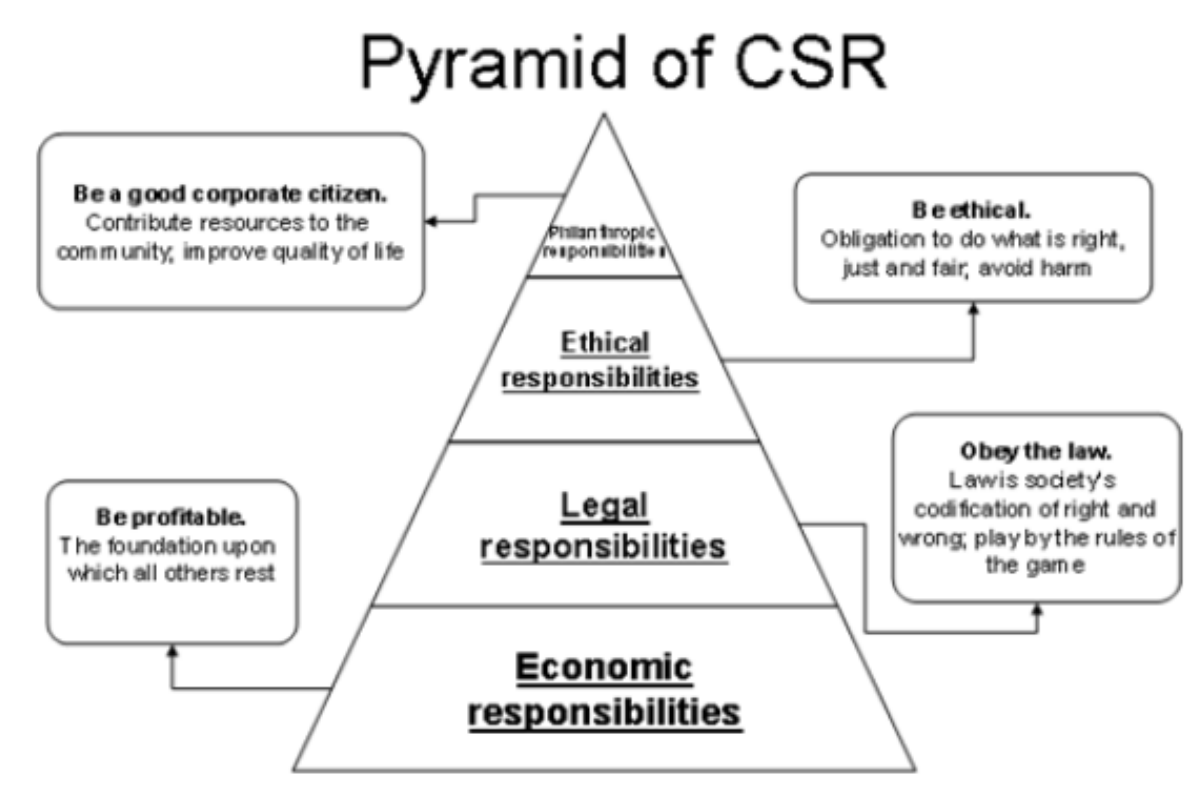

Figure 1. Pyramid of CSR

Source: Caroll (1979)

\subsection{University Social Responsibility (USR)}

Here, we will try to identify the concept of USR, to understand how this concept emerges and how it can operate. Then, we will be able to define its components and practices. After this, effects of this integrative approach for university and social responsibility will be detailed and measured.

The main idea of USR is based on the nature of the university, considered as an organization which is in society, and so which must contribute to CSR (Vallaeys, 2013). Meanwhile, Parson 
(2014) demonstrates that, in this way, it is different because, 'the university must be responsible towards students and staff or towards stakeholders, partners and its community'. Vasilescu et al. (2010) argue that the university must undertake many reforms to reinforce its ability to face new challenges and develop a third mission in 'which the university engages with society' (Howard and Sharma, 2006) through a social role.

USR has been considered to comprise practices related to corporate social responsibility (Ahmad, 2012; Nejati et al., 2011), as dimensions (Dima et al., 2013), and as interactions between external factors and public relations (Karimi, 2013) on different levels (Tetrevova and Sabolova, 2010).

In line with to the objective of this research, we will admit the approach of Chen (2015), termed SCOPE, and which seems to be an approach with different components; social, sub-social, cognitive, organizational, philanthropic, economic, ethical, environmental and educational.

In this context, USR acts as a key player for social changes (Chen et al., 2015).

However, this seems to be difficult if we consider that social responsibility is a multidimensional concept. The question of how this can be established needs to be clarified. Our literature review, as shown before, admits that the USR can be translated through dimensions, components and practices. The most appropriate approach here is to consider it as a system of management practices "of the educational cognitive, labour, and environment impact in an interactive dialogue with society and its communities' (Esfijani, Hussain and Chang, 2012). This impact must be considered as indirect because the effect of these practices in terms of development is not clear. We suppose that USR promotes a corporate social responsibility defined by ethical values and respect for the community, employees, the environment, shareholders and stakeholders.

Vallaeys (2013) states that USR:

- A responsibility of institutions' action and behaviour influenced by and caused to society

- Requires management practice

- Its objective is to make society sustainable

- Seeks to promote sustainable forms of development

- Has a legal obligation

Martinez-Usarralde et al. (2017) consider that all of this process depends on students who agree that the university can offer academic citizenship education in response to social needs, by contributions to social projects outside the university and by encouragement to engage in research projects aimed at solving societal and environmental problems. Gomez et al. (2018) develop this concept as a project in which students, faculty and administrative personnel must participate, including the essential stakeholders in higher education. However, this research is only in connection with a private university. Our approach integrates both of these aspect, with: USR as a project which needs cooperation between all partnerships of the university, including the students.

\subsection{Sustainable Development Awareness (SD)}


Whatever the definition of SD, we must underline the continuity of development. This sustainability of development is obliged to serve actual needs without compromising the needs of further generations (Baumgartner and Ebner, 2006).

Keiner (2005) defines three invariants of SD; social, economic and environmental. In this state, we will consider the awareness and knowledge about sustainable development. In other worlds we are looking for the perception of sustainable development in order to contribute in its definition.

\section{Conceptual Framework and Hypothesis}

\subsection{USR for a Better CSR}

As previously described, the university here is considered as an organization which exists and coexists in a social and economic environment, and has in consequence to act and react with different members of the society: it must face concurrence and serve the 'customer' to survive. So, it has a double deal, which is difficult, because while, as we know, university is at the 'heart' of society, at the same time, it must satisfy students as customers who will continue after graduation to build well-being in society.

It can therefore be admitted that university is at the same time an actor and a subject of society's well-being. As the number of unemployment graduate students increases, universities must redefine their traditional function as a simple academic agent and must interact with society in order to improve the quality of learning and adapt its knowledge process to the needs of labour markets and society (Vallaeys, 2013). As a social agent, universities must also act and react society, being active and engaging in social movements with the local and global community (Reiser, 2007).

This brief literature review highlights the point that social responsibility is considered a necessity for development and that the university must contribute to the implementation of this.

The concept of university social responsibility represents, according to our literature review, an integrative and dynamic approach to university with not only the university community but also with society: the university can be considered at the same time as a social partnership, a player for social change and a stimulator for social improvement (Esfijani et al., 2012).

Social responsibility means that the organization has an impact on society and environment based on its decisions and activities (Duckworth \& Rosemond, 2010). So, to be social, a university must be able to develop and engage a new approach which demonstrates their commitment to society. In the same vein, Vallaeys (2013) identifies the "key features" of SR of the university: actions and behaviours which have influenced and caused changes in society, management practices, working in coordination with legal obligations and finally coordination between stakeholders. We can conclude that there is an interaction between USR and CSR, and can define also a number of common dimensions between these two concepts.

\section{H1: USR contribute positively to the improvement of CSR}

Valazquez et al. (2006) define USR as "a higher educational institution [...] that addresses, involves and promotes [...] effects generated in the use of their resources in order to fulfil its functions of teaching, research, outreach and partnership and stewardship in ways to help society make the transition to a sustainable lifestyle". 
Muijen (2004) insist on the role of the critical education provided by universities for students to stimulate the development of human society, added to awareness of the social responsibility for generations.

\section{H1.1 - USR, through its educational impact, increases ethical responsibility}

H1.2 - USR, through its cognitive impact, increases philanthropic responsibility

Lindqvist (2012) presents a perspective of cognitive and educational impact based on innovation and technology, which can enhance the development of local industry and, in consequence, a variety of good products for society.

\section{H1.3 - USR in its organizational impact increase the economic responsibility.}

\subsection{Interdependence Between CSR and SD}

Vasilescu et al. (2010) consider that SR 'has become part of the global discussion about competitiveness and sustainability in the circumstance of globalization'.

WBCSD (2000) consider that CSR is 'a continuing commitment by business to behave ethically and contribute to economic development while improving the quality of life of the workforce and their families as well as of the local community and society at large'. Added to this, CSR considers that every social institution is 'obliged' to generate outcomes associated with involvement in society (Wood, 1991).

Our literature review shows that CSR and SD are interdependent.

H2. The development of CSR positively affects $S D$

\subsection{USR and SD}

Lo et al. (2017) consider that USR is in perpetual interconnection with society for sustainable human development, naming this process 'a dialogue'.

A dialogue, as defined, supposes that two parties interchange messages for the mutual transmission of information and a balanced situation. In this way, we can suppose that USR affects sustainable development (in the human dimension) and needs feedback in a retroactive approach.

USR contributes to the generation of a higher civil citizenship. Students and staff of a university entertain 'a social services to their local community and promote [...] local and global sustainable development' (Vasilescu et al., 2010). Razak et al. (2017) consider universities as 'the most important societal institution' which contributes to sustainable development goals and insists on the greater effect of and strong relationship between the university as a social agent and SD.

We can admit, based on this, that university as a generator of qualified and conscious human resources based on the three missions set out in the first section can contribute to SD. With a cultivated human resource who recognize the importance of society, and a high level of citizenship, if they are engaged in such a process, the research mission can guide them to create and innovate for the achievement of sustainable development goals. The third mission of the university as a strategic partnership of social responsibility can be represented by the creation of a new project which enhances environmental, social and economic development.

Reiser (2007) mainly considers how to manage university using a social optic but, in any case insists on the social impact of USR on sustainable human development. 
A citizenship perspective on the university was developed by Vasilescu et al. (2010). Based on this research, the university must develop a voluntary commitment to society by teaching an ethical approach to students and encouraging staff to "provide social services to their local community or to promote ecological, environmental commitment for local and global sustainable development."

H3. USR contributes positively to SD

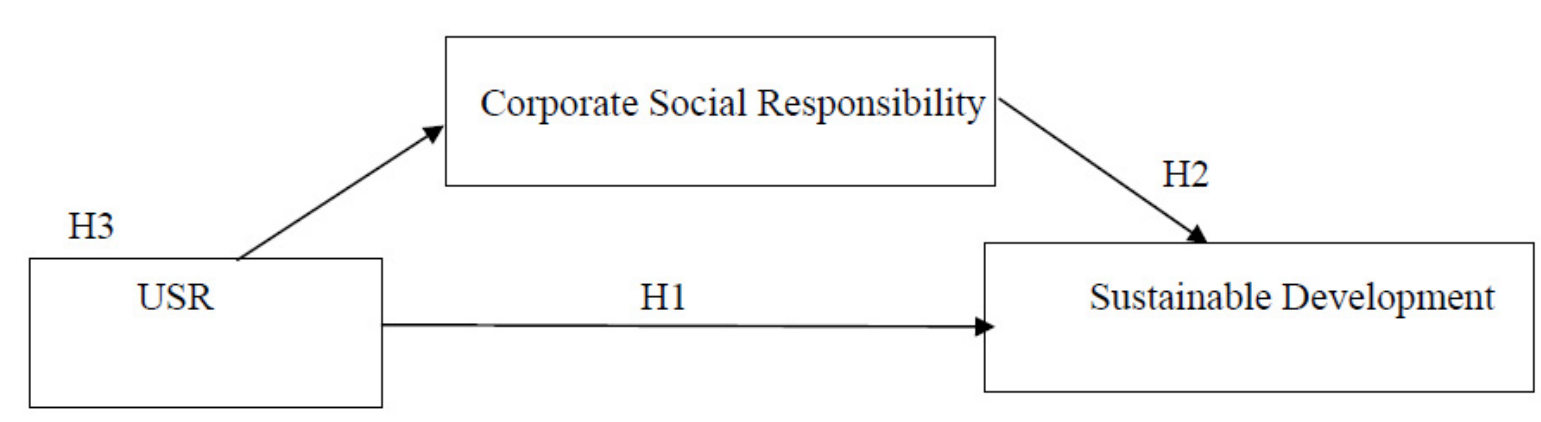

Figure 2. Research model

\section{Methodology}

In line with the objective of this research, we will adopt a qualitative approach: specifically, a casual approach based on the structural equation model will be adopted. A questionnaire will be used in order to collect data, and the items included will be detailed. Data analysis will be done by LISREL 8.52, taking into account the approach of Baron and Kenny (1986) for the test of mediating effect.

Measuring instruments

A structured questionnaire is elaborated and administered. Four mains parts are included: the first contains all information about respondents, such as age and profile; the second is about USR. The main objective of this section is to identify the components of this concept and determine how far it is applied at CBE (the College of Business and Economics). To measure USR, we used a different item identified in the literature: social engagement, represented by teaching and research mission (Shek et al., 2017) which provide development of social consciousness (Berman, 1990). In all, 27 items are adopted through the literature review and represent the different impacts of USR cited earlier in this article. The respondent is asked to rate their degree of agreement according to a Likert scale from 1 to 5.

The second part of the survey is related to CSR, using five dimensions in order to assess the importance of this variable for respondents and the most important determinant of this in our sample. Items related to the CSR are used based on the scale developed by Montazeri et al. (2017), for which the scale was adjusted to suit the context of study after a pre-test to guarantee internal coherence. The last part of the questionnaire enumerates items of SD linked to three main components; social, economic and environmental. The scale defined by Chow and Chen 
(2012) to measure SD is the most appropriate for this research because it has already been tested in the teaching field.

It should be clarified that all items were translated into Arabic and administered for students, teachers and staff at the university. one advantage of the sample comes from the fact that these respondents are simultaneously members of the university and actors in society, so they can have an exhaustive approach to our objective of research. A focus group was conducted to translate items from English to Arabic. We then tested the questionnaire before the final administration. In all, 25 pre-tests of the questionnaire with Arabic items were conducted established and minor modifications were done in line with feedback from respondents.

The final version of the questionnaire was administered to 230 members of the university. A descriptive analysis of the data was performed, and the results will be detailed in the next section. The survey was administered face to face in addition to by e-mail, to speed up the data collection process.

After the operationalization of variables, our model of research can be detailed as below:

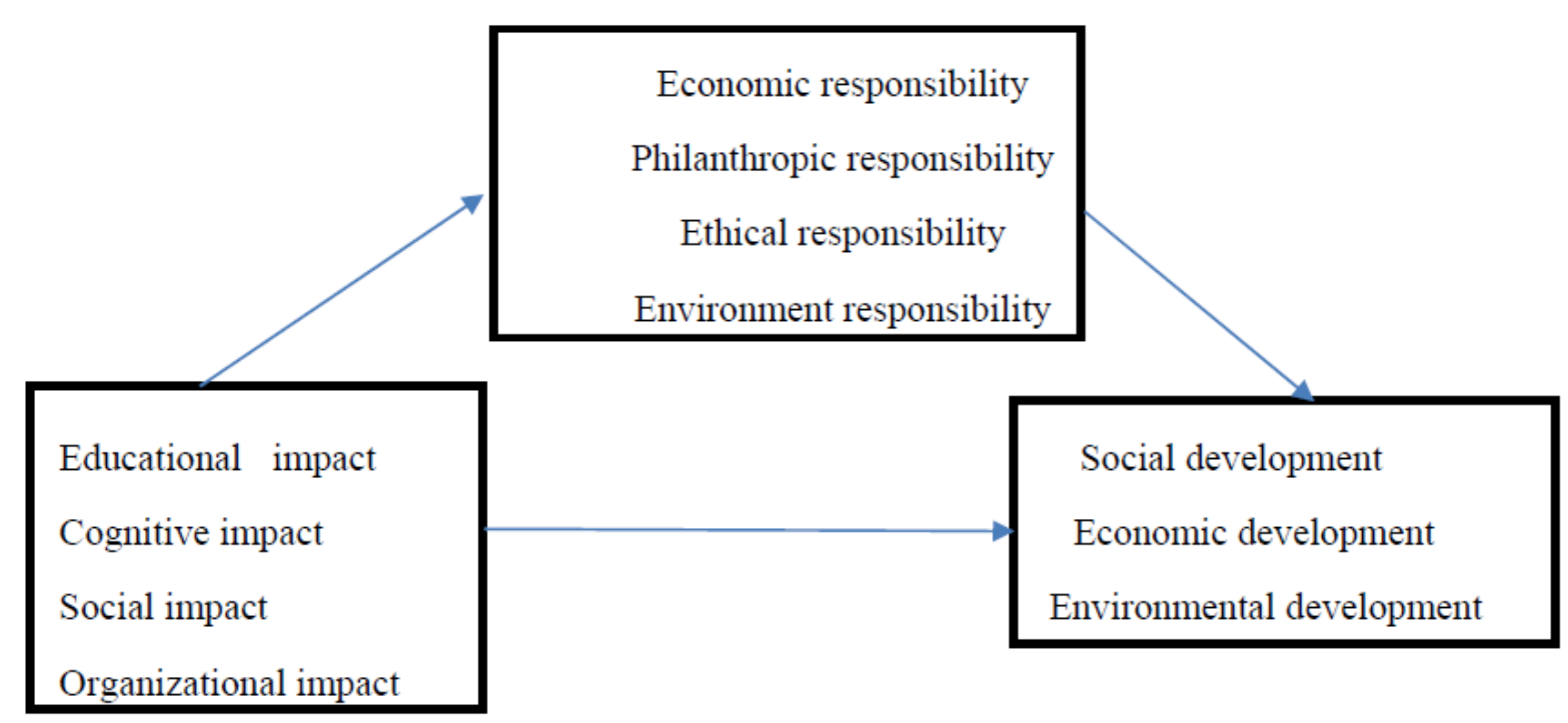

Figure 3. Dimensions of research

The next section presents results for the hypotheses tested, as well as a descriptive analysis of our sample. We have to specify that relations between the variables in this model are multiple. Our literature review reveals a total interdependence between the dimensions selected. Based on this, our objective will not only be to verify the hypotheses but to identify a critical path for SD from USR.

\section{Results}

The quantitative approach, in the context of SEM, needs two main steps; an exploratory and a confirmatory approach. The exploratory approach is used to identify factors in the variables used and identified based on the theoretical model with component analysis. Cronbach's Alpha and variance for each dimension is analysed. Our objective was to purify items for the next step, being the confirmatory approach. 
The confirmatory approach requires two levels: a first order confirmatory factor analysis between dimensions and items, termed the measure model; and a second order confirmatory factor analysis used to identify and verify the structural equation hypothesis between variables, factors and items.

\subsection{Descriptive Analysis}

The results of the descriptive analysis are shown in the three tables listed below: the first is related to profile, with $49.8 \%$ being students and $22 \%$ representing staff of the university.

Respondents between 18 and 35 years old formed the largest age group, with a rate of $50.2 \%$.

The majority of respondents were women, at 50.2\% (Table 3 ).

Table 1. Descriptive analysis related to respondents' profile

\section{PROFILE}

\begin{tabular}{llllll}
\hline & & Frequency & Percent & Valid Percent & Cumulative Percent \\
\hline Valid & 1 & 109 & 49.8 & 49.8 & 49.8 \\
& 2 & 22 & 10.0 & 10.0 & 59.8 \\
& 3 & 88 & 40.2 & 40.2 & 100.0 \\
& Total & 219 & 100.0 & 100.0 & \\
\hline
\end{tabular}

Table 2. Respondents' age

\begin{tabular}{llllll}
\hline AGE & \multicolumn{1}{c}{} & & \\
\hline & & Frequency & Percent & Valid Percent & Cumulative Percent \\
\hline Valid & 1 & 109 & 49.8 & 49.8 & 49.8 \\
& 2 & 110 & 50.2 & 50.2 & 100.0 \\
& Total & 219 & 100.0 & 100.0 & \\
\hline
\end{tabular}

Table 3. Respondents' gender

\section{GENDER}

\begin{tabular}{llllll}
\hline & & Frequency & Percent & Valid Percent & Cumulative Percent \\
\hline Valid & 1 & 109 & 49.8 & 49.8 & 49.8 \\
& 2 & 110 & 50.2 & 50.2 & 100.0 \\
& Total & 219 & 100.0 & 100.0 & \\
\hline
\end{tabular}

\subsection{Exploratory Analysis}

The second step is related to an exploratory approach, in order to identify dimensions of variables and the validity of items used in the questionnaire. 
Table 4 summarises the results of this analysis including total variance explained, number of items and internal coherence, based on Cronbach's alpha.

Table 4. Exploratory analysis results

\begin{tabular}{|c|c|c|c|c|c|}
\hline Variables & Factors & $\begin{array}{l}\text { Total of variance } \\
\text { explained }\end{array}$ & $\begin{array}{l}\text { Number of } \\
\text { items }\end{array}$ & $\begin{array}{l}\text { Alpha de } \\
\text { Cronbach }\end{array}$ & KMO \\
\hline \multirow[t]{3}{*}{ USR } & Educational impact & $22.1 \%$ & 5 & 0.812 & \\
\hline & Cognitive impact & $11.66 \%$ & 6 & 0.792 & \\
\hline & $\begin{array}{l}\text { Organizational } \\
\text { impact }\end{array}$ & $6.54 \%$ & 10 & 0.803 & 0.822 \\
\hline \multirow[t]{5}{*}{ CSR } & $\begin{array}{l}\text { Economic } \\
\text { responsibility }\end{array}$ & $33.14 \%$ & 5 & 0.720 & \\
\hline & $\begin{array}{l}\text { Philanthropic } \\
\text { responsibility }\end{array}$ & $17.47 \%$ & 5 & 0.813 & \\
\hline & Ethical responsibility & $8.40 \%$ & 4 & Deleted & 0.836 \\
\hline & Legal responsibility & $8.61 \%$ & 4 & 0.799 & \\
\hline & $\begin{array}{l}\text { Environmental } \\
\text { responsibility }\end{array}$ & Deleted & 4 & Deleted & \\
\hline \multirow[t]{3}{*}{$S D$} & Social & $31.77 \% \mathrm{~T}$ & 6 & 0.754 & \\
\hline & Economic & $12.32 \%$ & 6 & 0.815 & 0.850 \\
\hline & Environmental & Deleted & 10 & Deleted & \\
\hline
\end{tabular}

All items with a low factor contribution were deleted, including three items for organizational impact on university social responsibility measures. The third dimension of USR was also deleted, because its total variance explained was not acceptable. One item related to organizational impact, regarding the development of a hierarchical structural, was deleted, because without this item the internal reliability becomes 0.803 from 0.787 initially.

The social factor was deleted in this case due to the low level of alpha obtained here: this is related to the perception of respondents regarding social impact, which did not seem to be clear for them.

After purification of items, we can proceed at this level of research to the structural model.

\subsection{First Order Confirmatory Factor Analysis}

Our main objective here is to test the fit of our model. The results are presented according to the appearance of variables in the model discussed at the beginning of this paper. The USR will be treated initially, then the CSR, and finally the SD is analysed. 


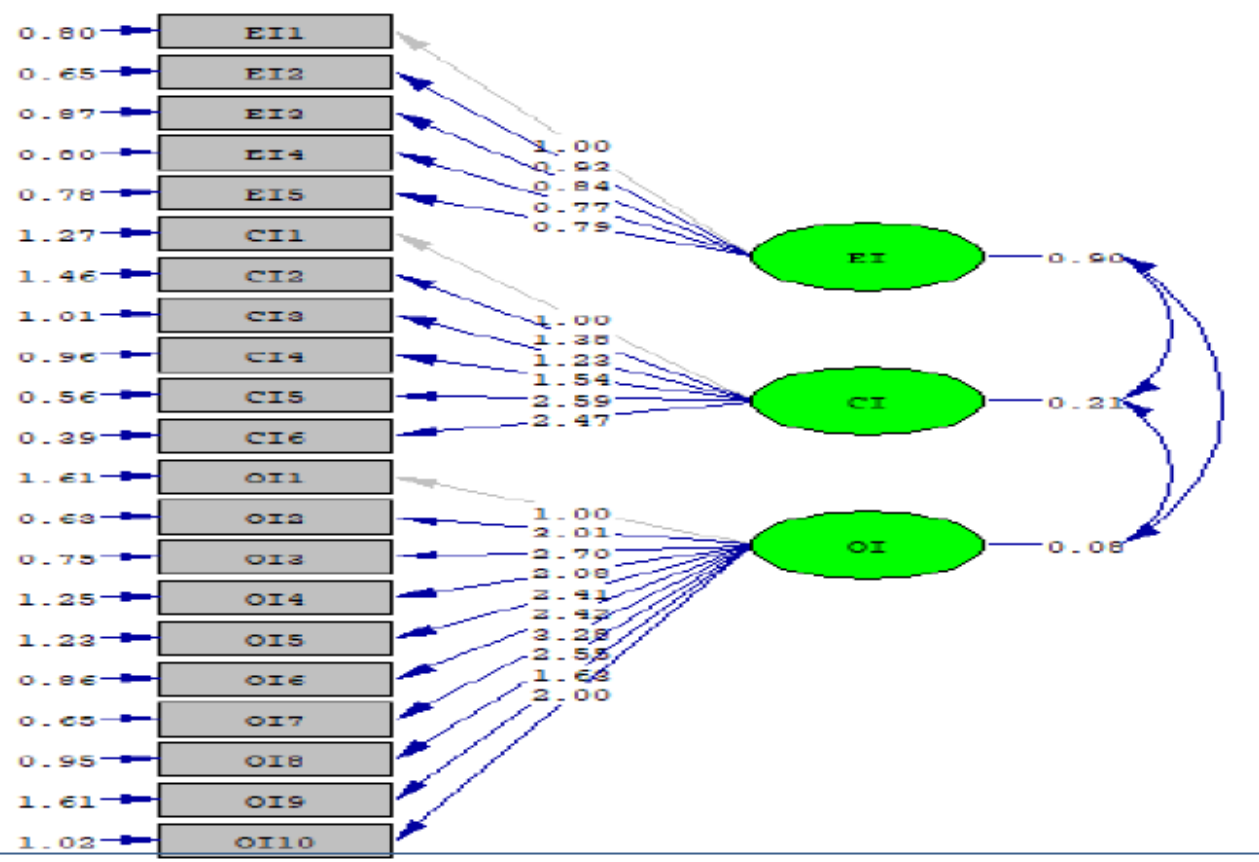

Figure 4. CFA of USR

Table 5. Goodness of fit of the model for USR

\begin{tabular}{lllllllll}
\hline Fitting index & CMIN/DF & GFI & AGFI & NFI & IFI & CFI & RMR & RMSEA \\
\hline Evaluation criterion & $<3$ & $>0.9$ & $>0.8$ & $>0.9$ & $>0.9$ & $>0.9$ & $<0.05$ & $<0.08$ \\
Test value & 2.7 & 0.905 & 0.818 & 0.912 & 0.920 & 0.921 & 0.014 & 0.072 \\
\hline
\end{tabular}

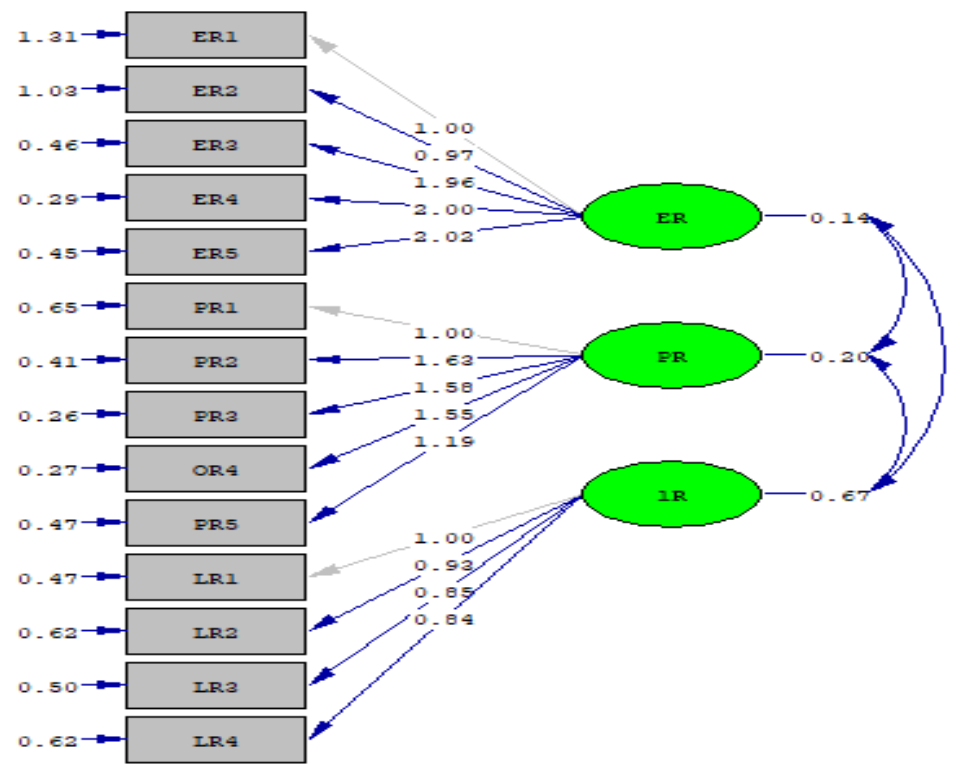

Figure 5. CFA of CSR 
Table 6. Goodness of fit of the model for CSR

\begin{tabular}{lllllllll}
\hline Fitting index & CMIN/DF & GFI & AGFI & NFI & IFI & CFI & RMR & RMSEA \\
\hline Evaluation criterion & $<3$ & $>0.9$ & $>0.8$ & $>0.9$ & $>0.9$ & $>0.9$ & $<0.05$ & $<0.08$ \\
Test value & 2.1 & 0.914 & 0.807 & 0.902 & 0.922 & 0.891 & 0.021 & 0.082 \\
\hline
\end{tabular}

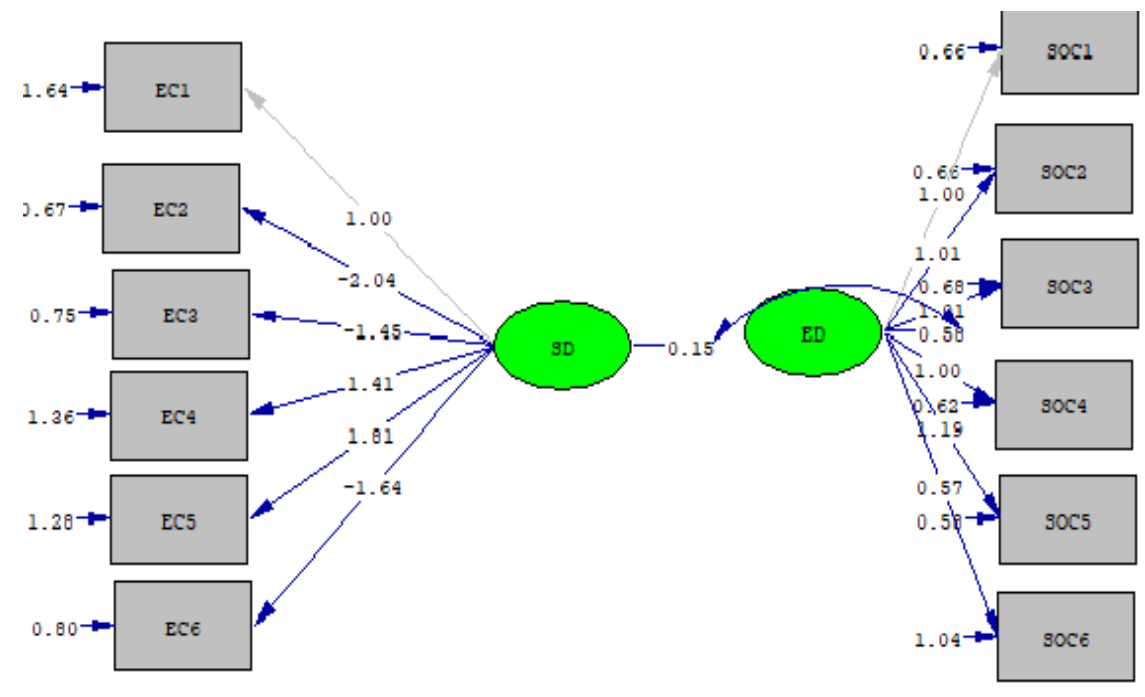

Figure 6. CFA of SD

Table 6. Goodness of fit of the model for CSR

\begin{tabular}{lllllllll}
\hline Fitting index & CMIN/DF & GFI & AGFI & NFI & IFI & CFI & RMR & RMSEA \\
\hline Evaluation criterion & $<3$ & $>0.9$ & $>0.8$ & $>0.9$ & $>0.9$ & $>0.9$ & $<0.05$ & $<0.08$ \\
Test value & 1.9 & 0.899 & 0.811 & 0.912 & 0.896 & 0.789 & 0.025 & 0.075 \\
\hline
\end{tabular}

\subsection{Second Order Confirmatory Factor Analysis and Hypothesis Test}

Finally, a hypothesis test with SEM is elaborated using LISREL 8.52, following the four steps defined and adopted by Baron and Kenny (1986), which seems to be the most appropriate approach for the mediation effect between an independent variable $\mathrm{X}$ and dependent variable $\mathrm{Y}$ by a mediating variable Xm.

The process needs to:

- Verify the relation between $\mathrm{X}$ and $\mathrm{Y}$ without $\mathrm{Xm}$, to demonstrate that a relation which can be mediated exists effectively;

- Elaborate a regression on Xm, with the mediating variable considered in this step as independent; 
- Conduct a regression between $\mathrm{Y}$, the dependent variable at the same time as $\mathrm{X}$ and $\mathrm{Xm}$. This test must demonstrate that the Xm variable affects $\mathrm{Y}$ through $\mathrm{X}$ and $\mathrm{Xm}$ is considered an explicative variable of Y (the dependent variable); and

- If the mediating effect exists, the relation which seems to be significant in the first step becomes invalid if $\mathrm{Xm}$ is integrated.

The mediating effect can be total or partial, but after this process, Baron and Kelly (1986) indicate that a Sobel test must be applied to ensure the significance of the mediating effect identified

Table 7. Hypothesis test

\begin{tabular}{llllll}
\hline Hypothesis & \multicolumn{2}{l}{ Path direction } & Path coefficient & P value & Result \\
\hline & USR $\rightarrow$ & CSR & 0.53 & $* * *$ & Pass \\
CSR $\rightarrow$ & SD & 0.20 & 0.010 & Pass \\
& USR $\rightarrow$ Sd & 0.69 & $* * *$ & Pass \\
\hline
\end{tabular}

Table 8. Results for mediating effects

\begin{tabular}{lllllll}
\hline Path & Direct path coefficients & Indirect effect & t-stat & Total effect & VAF & Mediation type \\
\hline 1 & 0.46 & 0.53 & 5.86 & 0.60 & 0.64 & Partial \\
\hline
\end{tabular}

\section{Conclusion}

This research contributes to the development of a measure scale for university social responsibility, based on the literature review. This scale may be considered and admitted by future research in this field: especially considering the difficulty of this concept, which is still at an 'exploratory stage' (Lo et al., 2017). Added to this, we have developed an exhaustive model in which university social responsibility and development are interconnected. This can constitute a user guide for academics and society, because it helps to fix how, in what and when university can be beneficial.

The main objective of this research is to identify the concept of university social responsibility in order to define a new approach for the university, which seems for a long time to have been an academic space only responsible for education and knowledge development. Therefore, we tried to define a dynamic and a social approach for the university based on its importance for development and sustainability, through the concept of corporate social responsibility.

Additionally, this study allows us too:

- Enumerate dimensions of USR in a practical approach

- Redefine the role of the university and reinforce its importance to society at different levels

- Identify the one best approach for development and sustainability for the university: for each dimension of sustainability and development, we will seek adequate practices and dimensions of university social responsibility 
- Reinforce the role of corporate social responsibility as a mediator in order to ensure the relation between USR and development which stimulates sustainability.

\section{References}

Ahmad, J. (2012). Can a university act as a corporate social responsibility (CSR) driver? An analysis. Social Responsibility Journal, 8(1), 77-86. https://doi.org/10.1108/174711112 11196584

Baron, R. M., \& Kenny, D. A. (1986). The Moderator-Mediator Variable Distinction in Social psychological Research: Conceptual, Strategic, and Statistical Considerations. Journal of Personality and Social Psychology, 51(6), 1173-1182. https://doi.org/10.1037/00223514.51.6.1173

Baumgartner, R., \& Ebner, D. (2010). Corporate Sustainability Strategies: Sustainability Profiles and Maturity Levels. Sustainable Development. https://doi.org/10.1002/sd.447

Caroll, A. B. (1979), A Three-Dimensional Conceptual Model of Social Performance, The Academy of Management Review, 4(4), 497-505. https://doi.org/10.5465/amr.1979.4498296

Chen, S-H. (2015). A strategic planning model for developing open educational resources. Dissertation submitted in partial fulfilment of the requirements for $\mathrm{PhD}$ in ETC. Bangkok, Thailand: Chulalongkorn University.

Chow, W. S., \& Chen, Y. (2012). Corporate sustainable development: Testing a new scale based on the Mainland Chinese context. Journal of Business Ethics, 105(4), 519-533. https://doi.org/10.1007/s10551-011-0983-X

Dima, A. M., Vasilache, S., Ghinea, V., \& Agoston, S. (2013). A model of academic social responsibility. Review of Administrative Sciences, 23-43.

Duckworth, A., \& Rosemond, A. M. (2010). Social responsibility: Failure mode effects and analysis. CRC Press/Taylor \& Francis. https://doi.org/10.1201/EBK1439803721

Esfijani, A., Hussain, F. K., \& Chang, E. (2012). An approach to university social responsibility ontology development through text analyses. Paper presented at the IEEE 5th International Conference on Human System Interactions, IEEE-HSI-2012. https://doi.org/ 10.1109/HSI.2012.10

Gomez, L., Alvarado Naveira, Y., \& Pujols Bernabel, A. (2018). Implementing University Social Responsibility in the Caribbean: Perspectives of Internal Stakeholders. Revista Digital de Investigación en Docencia Universitaria.

Howard, J., \& Sharma, A. (2006). Universities' Third Mission: Communities Engagement, B-Hert Position Paper, 11.

Karimi, M. R. (2013). Designing the conceptual model of social responsibility of the Azad University by public relation role. African Journal of Business Management, 7(1), 8-21.

Keiner, M. (2005), Re-emphasizing sustainable development — The concept of 'Evolutionability'. Environment Development and Sustainability, 6(4), 379-392. https://doi.org/10.1007/s10668-005-5737-4

Kumar, S., \& Roy, S. (2015). Corporate Social Responsibility in India: A Study in the Light of the Companies Act, 2013. In M. Vasan (Ed.), Corporate Social Responsibility. EduPedia Publications Pvt. Ltd 
Lo, C., Pang, W-H., Rose, X., \& Carolyn, P. (2017) University Social Responsibility: Conceptualization and Assessment Framework. In D. T. L. Shek, \& R. M. Hollister (Eds.), University Social Responsibility and Quality of Life, Springer. https://doi.org/10.1007/978-981 $-10-3877-8$ _ 4

Martínez-Usarralde, M. J., Lloret-Catalá, C., \& Mas-Gil, S. (2017). Responsabilidad Social Universitaria (RSU): Principios para una universidad sostenible, cooperativa y democrática desde el diagnóstico participativo de su alumnado. Archivos Analíticos de Políticas Educativas, 25(75), 1-25. https://doi.org/10.14507/epaa.25.2769

Muijen H. (2004). Corporate Social Responsibility Starts at University, Journal of Business Ethics, 53(1), 235-246. https://doi.org/10.1023/B:BUSI.0000039412.78194.1d

Nejati, M., Shafaei, A., Salamzadeh, Y., \& Daraei, M. (2011). Corporate social responsibility and universities: A study of top 10 world universities' websites. African Journal of Business Management, 5(2), 440-447.

Razak, A. D., Wan, C. D., \& Sirat, M. (2017). Juxtaposing Economic Progress with Sustainability in Mind: Issues and Way Forward for Universities, in Higher Education in the World 6: Towards a Socially Responsible University: Balancing the Global with the Local, Global University Network for Innovation (GUNI).

Reiser, J. (2007). Managing university social responsibility. International Sustainable Campus Network: Best Practices - Future Challenges.

Tetrevova, L., \& Sabolova, V. (2010). University stakeholder management and university social responsibility. WSEAS Transactions on Advances in Engineering Education, 7(7), 224-233.

Vallaeys, F. (2013). Defining social responsibility: A matter of philosophical urgency for university. Global university network for innovation.

Vasilescu, R., Barna, C., Epure, M., \& Baicu, C. (2010). Developing University Social Responsibility: A model for the challenges of the new civil society. Procedia Social and Behavioral Sciences, 2, 4177-4182. https://doi.org/10.1016/j.sbspro.2010.03.660

Velazquez, L., Munguia, N., Platt, A., \& Taddei, J. (2006). Sustainable university: What can be the matter? Journal of Cleaner Production, 14, 810-819. https://doi.org/10.1016/j.jclepro.2005. 12.008

Wood, D. J. (1991). Corporate Social Performance Revisited. The Academy of Management Review, 16, 691-718. https://doi.org/10.5465/amr.1991.4279616

\section{Glossary}

SD: Sustainable Development

CSR : Corporate Social Responsibility

USR : University Social Responsibility 


\section{Copyright Disclaimer}

Copyright for this article is retained by the author(s), with first publication rights granted to the journal.

This is an open-access article distributed under the terms and conditions of the Creative Commons Attribution license (http://creativecommons.org/licenses/by/3.0/). 